\title{
Facile Fabrication of Hierarchically Porous Carbonaceous Monoliths with Ordered Mesostructure via an Organic-Organic Self-Assembly
}

\author{
Chunfeng Xue, Bo Tu $(\bowtie)$, and Dongyuan Zhao $(\varangle)$
}

Department of Chemistry, Shanghai Key Lab of Molecular Catalysis and Innovative Materials, Key Laboratory of Molecular Engineering of Polymers, Laboratory of Advanced Materials, Fudan University, Shanghai 200433, China

Received: 14 December 2008/Revised: 11 January 2009/ Accepted: 12 January 2009

(C) Tsinghua University Press and Springer-Verlag 2009. This article is published with open access at Springerlink.com

\begin{abstract}
A simple strategy for the synthesis of macro-mesoporous carbonaceous monolith materials has been demonstrated through an organic-organic self-assembly at the interface of an organic scaffold such as polyurethane (PU) foam. Hierarchically porous carbonaceous monoliths with cubic $(\operatorname{Im} \overline{3} m)$ or hexagonal $(p 6 \mathrm{~mm})$ mesostructure were prepared through evaporation induced self-assembly of the mesostructure on the three-dimensional (3-D) interconnecting struts of the PU foam scaffold. The preparation was carried out by using phenol/formaldehyde resol as a carbon precursor, triblock copolymer F127 as a template for the mesostructure and PU foam as a sacrificial monolithic scaffold. Their hierarchical pore system was macroscopically fabricated with cable-like mesostructured carbonaceous struts. The carbonaceous monoliths exhibit macropores of diameter 100-450 $\mu \mathrm{m}$, adjustable uniform mesopores (3.8-7.5 $\mathrm{nm}$ ), high surface areas $\left(200-870 \mathrm{~m}^{2} / \mathrm{g}\right)$, and large pore volumes $(0.17-0.58) \mathrm{cm}^{3} / \mathrm{g}$. Compared with the corresponding evaporation induced self-assembly (EISA) process on a planar substrate, this facile process is a time-saving, labor-saving, space-saving, and highly efficient pathway for mass production of ordered mesoporous materials.
\end{abstract}

\section{KEYWORDS}

Self-assembly, synthesis, mesoporous materials, carbonaceous, monolith, templating, macroporous materials

\section{Introduction}

Porous carbonaceous materials are required for practical applications in supercapacitors, solar cells, hydrogen storage, high performance liquid chromatography (HPLC) separation, bioengineering, controlled drug delivery devices, and lithium ion batteries [1-3]. For industrially useful materials, the fabrication of porous carbons with the required morphology is important as well as having control of pore structure and wall composition. Monolithic materials with hierarchical pore structures facilitate the fast transportation of bulky molecules, because they can effectively access the mesopores and/ or micropores linked by a macroporous system [4-9]. Generally, hierarchically porous carbon monoliths are prepared by nanocasting monolithic hard templates, such as disordered or ordered microporous/mesoporous silica, or polystyrene microspheres [10-16]. However, the preparation of

Address correspondence to Dongyuan Zhao, dyzhao@fudan.edu.cn; Bo Tu, botu@fudan.edu.cn 
such ordered mesoporous silica monolith or stacked colloidal microsphere templates themselves is very difficult, although many strategies including the use of vacuum drying and liquid-paraffin-media have been developed [17, 18]. Moreover, it takes a long time to impregnate the carbon precursors into the monolithic mesochannels and to evaporate the solvent. The hierarchically porous materials with reverse-phase structure are slowly assembled in a relatively closed and confined space, and the carbon monolith is obtained after the carbonization and laborious removal of the templates. Obviously, such strategies for multimodal porous carbon monoliths are tedious and highly costly, and are not suitable for mass production of carbonaceous materials.

The solvent evaporation induced self-assembly (EISA) process has been developed for the preparation of ordered mesoporous carbonaceous films or powders [19-25]. It can be carried out by solution casting onto planar substrates to fabricate thin films. Mesoporous carbonaceous materials can be obtained after evaporation, thermopolymerization and carbonization. It is known that the phase interfaces, especially that provided by the substrate and air, play a key role in the self-assembly of ordered mesostructures. However, the EISA method is performed on an accessible and planar substrate and it is difficult to fabricate ordered mesoporous carbon monoliths by simply thickening the films, because disordered mesostructures are often produced in their middle-bottom part. Furthermore, organic-organic self-assembly on the planar substrate is not an economical route for mass production due to the difficulties in forming vast accessible spaces. Recently, an EISA procedure using a commercial decomposable scaffold containing macropores has been reported for the mass production of mesoporous carbon-silica composite materials [26]. This method may be a powerful pathway for self-assembly of carbonaceous materials, in which a liquid-gas interface is needed for the solvent evaporation. However, the preparation of carbonaceous materials with high-level symmetry mesostructures, e.g., $\operatorname{Im} \overline{3} m$, using this method still remains a challenge. To the best of our knowledge, hierarchically porous carbonaceous monoliths with ordered mesostructure prepared through EISA on an accompanying organic scaffold have not yet been reported.

In this paper, the synthesis of hierarchically porous carbonaceous monolith (HPCM) materials with ordered mesostructure is demonstrated by using EISA on a three-dimensional (3-D) macroporous sacrificial scaffold. Here, the commercially available and cheap polyurethane foam is used as a macroporous monolithic template to prepare carbonaceous monoliths by employing organicorganic self-assembly. 3-D cubic $(\operatorname{Im} \overline{3} m)$ and 2-D hexagonal $(p 6 \mathrm{~mm})$ carbonaceous mesostructures are macroscopically fabricated on the skeleton of the organic substrate. The resulting hierarchically porous carbonaceous monoliths have controllable macropores, uniform mesopores, high surface areas, and large pore volumes. The decomposable organic scaffold plays important roles in the process of solution evaporation, self-assembly, and macrostructure architecture.

\section{Experimental}

\subsection{Chemicals}

Polyether polyol-based polyurethane (PU) foam, an industrial product with a porosity of 50 ppi (pores per linear inch), was purchased from Shanghai Changda Foam Co. Ltd. The density of the PU foam was $0.02 \mathrm{~g} / \mathrm{cm}^{3}$. Triblock copolymer poly(ethylene oxide)-b-poly(propylene oxide)- $b$-poly(ethylene oxide) Pluronic F127 $\left(\mathrm{EO}_{106} \mathrm{PO}_{70} \mathrm{EO}_{106}, \mathrm{MW}_{\mathrm{av}}=12,600\right)$ was purchased from Aldrich. Other chemicals were purchased from Shanghai Chemical Co. All chemicals were used as received without further purification.

\subsection{Preparation of carbon precursor}

Resol with low molecular weight (MW $=500-5000)$ derived from polymerized phenol and formaldehyde was used as the carbon precursor. For a typical preparation: phenol (305 g) was completely melted at $42{ }^{\circ} \mathrm{C}$ in a flask, then $20 \mathrm{wt} \%$ aqueous $\mathrm{NaOH}(65$ g) solution was slowly added over $20 \mathrm{~min}$ to the above flask with stirring. After that, $37 \mathrm{wt} \%$ formalin solution (525 g) was added, and the mixture was polymerized with stirring at $70-72{ }^{\circ} \mathrm{C}$ for $1 \mathrm{~h}$. After

\section{型 Springer}


cooling the mixture to room temperature, its $\mathrm{pH}$ value was adjusted to neutral (7.0) by using 2.0 $\mathrm{mol} / \mathrm{L} \mathrm{HCl}$ solution. After the water was removed under vacuum below $52{ }^{\circ} \mathrm{C}$, the product was dissolved in ethanol to give a concentration of 40 $w t \%$. A centrifugation process was performed in order to remove solid $\mathrm{NaCl}$.

\subsection{Synthesis of monoliths}

A hierarchically porous carbonaceous monolith with a body-centered cubic mesostructure (HPCM-1) was prepared as follows. Pluronic F127 (100 g), ethanol (700 g), and resol solution (500 g) formed from phenol (122 g) and formaldehyde (78 g) were mixed in turn with continuous stirring over $1 \mathrm{~h}$. The resulting homogeneous solution was coated onto PU foam with a total volume of $6100 \mathrm{~cm}^{3}$. The air bubbles inside the PU foam scaffold were removed by frequently squeezing the scaffold during the infusion of the sol solution. A continuous rotation of the infused PU foam in flowing air was carried out to ensure that the precursors were uniformly coated on the struts of the PU foam. After the ethanol was evaporated completely at $28{ }^{\circ} \mathrm{C}$, samples were heated at $130,350,600$, and $900{ }^{\circ} \mathrm{C}$ for $3 \mathrm{~h}$ in a nitrogen filled tube oven. The resulting samples are denoted as HPCM-1-130 (as-made), HPCM-1-350, HPCM-1-600 and HPCM-1-900, respectively. The heating rate was $1{ }^{\circ} \mathrm{C} / \mathrm{min}$ below $600{ }^{\circ} \mathrm{C}$ and $5^{\circ} \mathrm{C} / \mathrm{min}$ above $600{ }^{\circ} \mathrm{C}$.

Hierarchically porous carbonaceous monoliths with 2-D hexagonal mesostructure (HPCM-2) were prepared following a similar procedure. Pluronic F127 (100 g) was dissolved in ethanol (850 g) and resol solution $(250 \mathrm{~g})$ derived from phenol (61 g) and formaldehyde ( $39 \mathrm{~g}$ ) at $28-30{ }^{\circ} \mathrm{C}$ with stirring for $60 \mathrm{~min}$. The resulting homogeneous solution was coated on PU foam with a total volume of $5650 \mathrm{~cm}^{3}$. After further thermopolymerization, calcination, and carbonization, hierarchically porous carbonaceous monoliths with different properties were obtained.

\subsection{Measurements}

Small-angle X-ray scattering (SAXS) data were collected on a Nanostar U small-angle X-ray scattering system using $\mathrm{Cu} \mathrm{K} \alpha$ radiation at $40 \mathrm{kV}$ and $35 \mathrm{~mA}$. The $d$-spacing values were calculated from the formula $d=2 \pi q^{-1}$. The unit cell parameters were calculated using the formula $a_{0}=(\sqrt{2}) d_{110}$ and $a_{0}=2 d_{10}(\sqrt{3})^{-1}$ for HPCM-1 and HPCM-2, respectively, where $d_{110}$ and $d_{10}$ represent the $d$-spacing values of the 110 and 10 reflections. Powder X-ray diffraction (XRD) patterns were recorded on a Bruker D4 powder $\mathrm{X}$-ray diffractometer using $\mathrm{Cu} \mathrm{K} \alpha$ radiation at $40 \mathrm{kV}$ and $40 \mathrm{~mA}$. Transmission electron microscopy (TEM) experiments were done on a JEOL 2011 microscope operated at $200 \mathrm{kV}$. The ground samples for TEM measurements were suspended in ethanol and supported on a carbon-coated copper grid. Scanning electron microscopy (SEM) images were collected with a Philips XL30 electron microscope operated at $20 \mathrm{kV}$. A thin gold film was sprayed on the samples before the images were collected. $\mathrm{N}_{2}$ sorption isotherms were measured with a Micromeritics Tristar 3000 analyzer at $77 \mathrm{~K}$. Before the measurements, all samples were degassed at $180^{\circ}$ $\mathrm{C}$ in vacuum for at least $6 \mathrm{~h}$. By using the Barrett -Joyner-Halenda (BJH) model, the pore volumes and pore size distributions were derived from the adsorption branches of isotherms. The BrunauerEmmett-Teller (BET) method was utilized to calculate the specific surface areas. The thermal decomposition behavior and weight changes of the samples were monitored by using a Mettler Toledo TGA-SDTA851 analyzer from 25 to $900{ }^{\circ} \mathrm{C}$ in nitrogen flow with a heating rate of $5{ }^{\circ} \mathrm{C} / \mathrm{min}$. The $\mathrm{C}, \mathrm{H}$, and $\mathrm{N}$ contents were measured on a Vario EL III element analyzer. Fourier transform infrared (FT-IR) spectra were collected on a Nicolet Fourier spectrophotometer.

\section{Results and discussion}

\subsection{Fabrication of the hierarchically porous monolith materials}

The simple fabrication process for the hierarchically porous monolith was carried out as follows (Scheme 1): firstly, the macroporous PU foam was used as a monolithic scaffold and coated with an ethanol solution containing the carbon precursor and triblock copolymer template. The commercial PU foam 
with ramified struts provides an abundance of interfaces for organic -organic self-assembly. Secondly, further thermopolymerization at high temperature was performed after solvent EISA. The open macrostructure of the PU foam scaffold facilitates the rapid evaporation of the solvent. Thirdly, after calcination and carbonization, the copolymer template and thermally decomposable scaffold were removed, the mesopores of the carbonaceous coat were exposed and the skeleton of the sacrificial scaffold was replicated; this differs from the reverse-phase replication of the complicated nanocasting procedure. Finally, hierarchically porous polymer/carbon monoliths were obtained (Scheme 1).

\section{$2.2 \operatorname{Im} \overline{3} m$ mesostructure of HPCM-1}

No diffraction from an ordered mesostructure was observed in

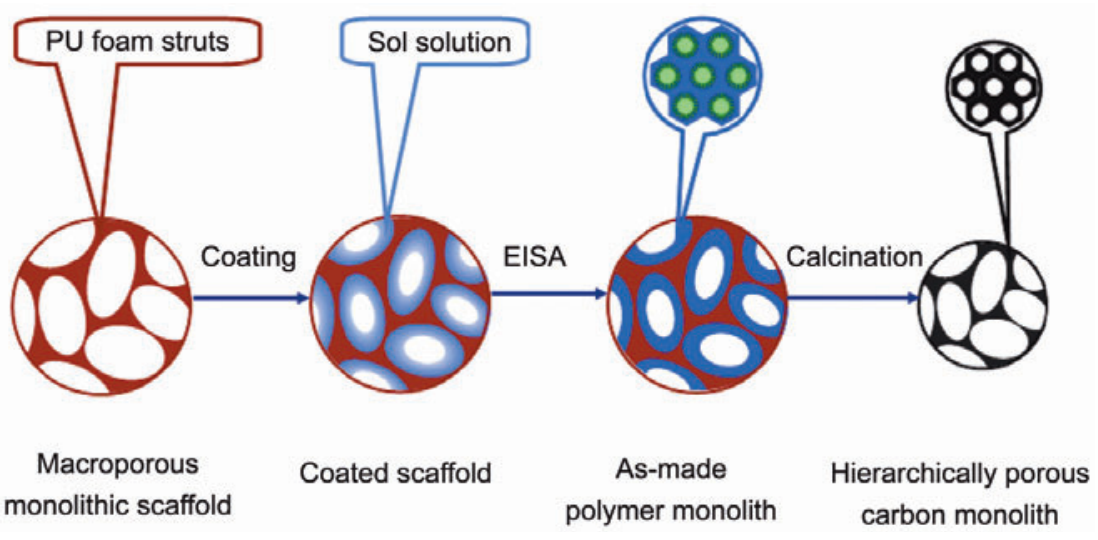

Scheme 1 Fabrication of hierarchically porous carbonaceous monoliths templated by PU foams via an EISA method

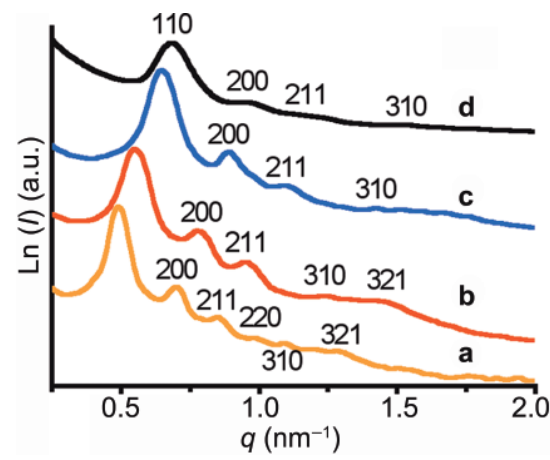

(a)

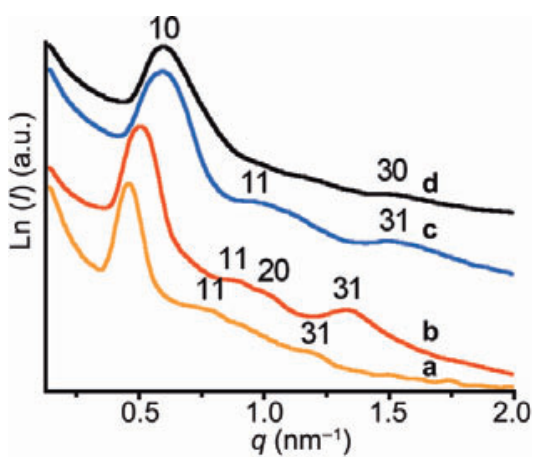

(b)

Figure 1 SAXS patterns of hierarchically porous carbonaceous monoliths HPCM-1 (a) and HPCM-2 (b) calcined at (a) 130, (b) 350, (c) 600, and (d) $900{ }^{\circ} \mathrm{C}$

the SAXS pattern of PU foam scaffolds, clearly indicating a disordered structure (see Electronic Supplementary Material, Fig. S-1). The SAXS pattern of the hierarchically porous carbonaceous monolith HPCM-1-130 prepared by coating a solution of resol and copolymer on the ramified strutted surface of the PU foam scaffold shows three well-resolved scattering peaks and three weak ones (Fig. 1(a) a). The ratios of the $q$-values are exactly $1: \sqrt{2}: \sqrt{3}: \sqrt{4}$ : $\sqrt{5}: \sqrt{7}$ and the peaks can be indexed as 110, 200, 211, 220,310 , and 321 reflections, respectively, associated with the body-centered cubic $\operatorname{Im} \overline{3} m$ symmetry. A unit cell parameter $\left(a_{0}\right)$ of $18.1 \mathrm{~nm}$ can be calculated from the SAXS pattern. The results indicate that highly ordered mesoporous carbonaceous materials can be successfully prepared through organic-organic selfassembly on the macroporous monolithic scaffold. After calcination at $350{ }^{\circ} \mathrm{C}$ for $3 \mathrm{~h}$ in nitrogen to remove the triblock copolymer template, the SAXS pattern of the resulting HPCM-1-350 monolith also shows three well-resolved scattering peaks and two weak ones (Fig. 1(b) b), suggesting a stable ordered body-centered cubic mesostructure. The calculated value of the parameter $a_{0}$ is $16.2 \mathrm{~nm}$, indicating that there is about $10.5 \%$ framework shrinkage due to further crosslinking and template removal during the calcination process (Table 1). With further carbonization at $600{ }^{\circ} \mathrm{C}$ in nitrogen, despite the transformation of the polymer into textured carbon, the SAXS pattern of the resulting HPCM-1-600 still shows three resolved scattering peaks with obvious shifts towards high $q$ values (Fig. 1(a) c). The calculated value of $a_{0}(13.7 \mathrm{~nm})$ from the patterns also reflects the further framework shrinkage (13.8\%) upon calcination. Even after being calcined at $900{ }^{\circ} \mathrm{C}$ in $\mathrm{N}_{2}$ to bring about further carbonization, the carbonaceous monolith HPCM-1-900 shows four scattering peaks in the SAXS patterns (Fig. 1(a) d), indexed as 110, 200, 211, and 220 planes, suggesting that the mesostructure of the hierarchically porous

\section{基 Springer}


Table 1 Lattice parameter $\left(a_{0}\right)$, pore diameter $(D)$, wall thickness $(t)$, BET surface area $\left(S_{\mathrm{BET}}\right)$, pore volume $\left(V_{\mathrm{p}}\right)$, ratio of framework shrinkage $\left(R_{\mathrm{FS}}\right)$, and elemental analysis results for mesoporous carbon monolith materials with cubic (HPCM-1) or hexagonal (HPCM-2) structures calcined at different temperatures

\begin{tabular}{|c|c|c|c|c|c|c|c|c|c|c|}
\hline Sample code & $\begin{array}{c}a_{0} \\
(n m)\end{array}$ & $\begin{array}{c}D \\
(\mathrm{~nm})\end{array}$ & $\begin{array}{c}t \\
(\mathrm{~nm})\end{array}$ & $\begin{array}{c}S_{\text {BET }} \\
\left(\mathrm{m}^{2} / \mathrm{g}\right)\end{array}$ & $\begin{array}{c}V_{p} \\
\left(\mathrm{~cm}^{3} / \mathrm{g}\right)\end{array}$ & $\begin{array}{l}R_{\mathrm{FS}} \\
(\%)\end{array}$ & $\begin{array}{c}\mathrm{N} \\
(\mathrm{wt} \%)\end{array}$ & $\begin{array}{c}C \\
w t \%)\end{array}$ & $\begin{array}{c}\mathrm{H} \\
(w t \%)\end{array}$ & $\begin{array}{c}0 \\
\text { (wt\%) }\end{array}$ \\
\hline HPCM-1 & 18.1 & & & & & & & & & \\
\hline HPCM-1-350 & 16.2 & - & - & - & - & 10.5 & 2.6 & 75.1 & 5.3 & 17.0 \\
\hline HPCM-1-600 & 13.7 & 4.4 & 7.5 & 480 & 0.24 & 24.3 & 2.1 & 77.3 & 8.7 & 11.9 \\
\hline HPCM-1-900 & 13.0 & 3.8 & 7.5 & 517 & 0.33 & 28.2 & 1.2 & 84.4 & 2.1 & 12.3 \\
\hline HPCM-2 & 16.3 & & & & & & & & & \\
\hline HPCM-2-350 & 14.4 & 7.5 & 6.9 & 200 & 0.17 & 11.6 & 4.3 & 77.1 & 5.1 & 13.5 \\
\hline HPCM-2-600 & 12.2 & 5.4 & 6.8 & 540 & 0.38 & 25.1 & 5.6 & 83.0 & 1.9 & 9.5 \\
\hline HPCM-2-900 & 12.1 & 4.9 & 7.2 & 870 & 0.58 & 25.8 & 1.9 & 75.4 & 2.1 & 20.6 \\
\hline
\end{tabular}

$a_{0}$ was calculated from SAXS results. $D$ was calculated by the BJH model from the adsorption branches of the isotherms. $t$ was calculated by the formulae $t=\sqrt{3} a_{0} / 2-D$ and $t=a_{0}-D$ [27] for HPCM-1 and HPCM-2, respectively, where $a_{0}$ represents the lattice parameter and $D$ represents the pore diameter determined by the BJH model. $S_{\mathrm{BET}}$ was calculated by the BJH model from the sorption data. The $R_{\mathrm{FS}}$ values are based on the asmade samples HPCM-1 and HPCM-2.

monolith HPCM-1-900 is thermally stable; the calculated unit cell parameter is $13.0 \mathrm{~nm}$. Based on the HPCM-1-130 precursor, the overall framework shrinkage during formation of HPCM-1-900 is $28.2 \%$. Given the obvious shrinkage upon high-temperature treatment, the reduction in intensity of the reflection peaks for the ordered mesostructure could be due to the evolution of mesopore wall thickness and pore diameter [28].

TEM images of the hierarchically porous carbonaceous monolith HPCM-1-600 display large domains of typical patterns for a body-centered cubic mesostructure viewed along the [111], [100], and [110] directions (Figs. 2(a)-2(c)), further confirming the highly ordered cubic $\operatorname{Im} \overline{3} m$ structure. The unit cell parameter deduced from TEM images is $13.5 \mathrm{~nm}$, in accordance with the value from SAXS data. Arrayed cage-like pores are also revealed. The fast Fourier transform (FFT) diffractograms (insets) also show the typical ordered cubic $\operatorname{Im} \overline{3} m$ structure. Electron diffraction (ED) images and high-angle XRD patterns (the data are not shown here) confirm that the HPCM-1-600 framework is composed of amorphous carbonaceous species. After carbonization at $900{ }^{\circ} \mathrm{C}$, the resulting carbonaceous monolith HPCM-1-900 still shows a clear $\operatorname{Im} \overline{3} m$ mesostructure (the TEM image is not shown here). All the results show that mesostructure of hierarchically porous carbonaceous monoliths has a good thermal stability, which is consistent with the SAXS results.

After calcination at $600{ }^{\circ} \mathrm{C}$ in nitrogen, $\mathrm{N}_{2}$ sorption isotherms of the resulting HPCM-1-600 sample exhibit type IV curves with obviously capillary condensation steps (Fig. 3(a)), consistent with their

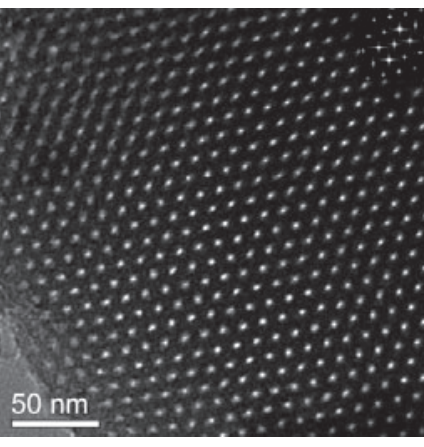

(a)

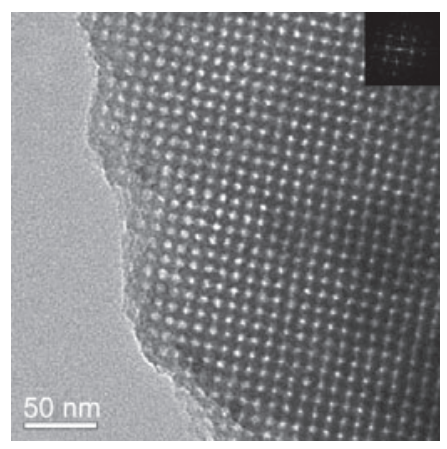

(b)

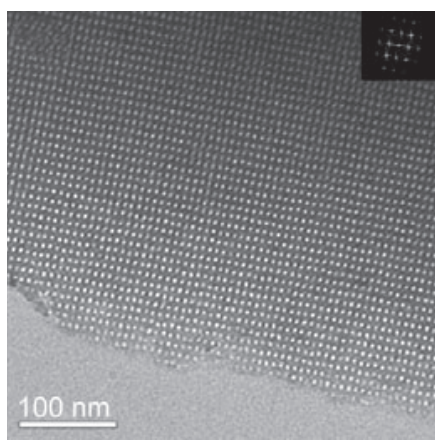

(c)

Figure 2 TEM images of hierarchically porous carbonaceous monolith HPCM-1-600 viewed along the [111] (a), [100] (b), and [110] (c) directions. The insets are the corresponding FFT diffractograms 


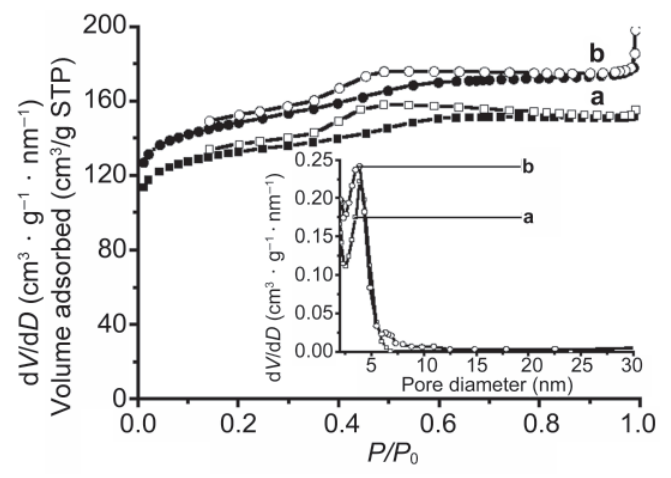

Figure $3 \quad \mathrm{~N}_{2}$ sorption isotherms and pore size distributions (inset) of (a) HPCM-1-600 and (b) HPCM-1-900. P/P $P_{0}$ is ralative pressure

uniform mesostructures indicated by SAXS and TEM. The adsorption and desorption branches of HPCM-1-600 deviate at low relative pressure, which is related to the asymmetric shrinkage of pores. The carbonaceous monolith HPCM-1-600 shows a BET surface area of $480 \mathrm{~m}^{2} / \mathrm{g}$ (Fig. 3(a)) and a narrow pore size distribution with a mean value of $4.4 \mathrm{~nm}$ (Fig. 3, inset). The $\mathrm{H}_{2}$ hysteresis loop of the hierarchically porous carbonaceous monolith HPCM-1-900 implies it has cage-like channels, corresponding to a body-centered cubic mesostructure. The capillary condensation step of HPCM-1-900 is shifted slightly to lower relative pressure, which is related to the slight reduction in aperture size to $3.8 \mathrm{~nm}$ (Fig. 3, inset), resulting from framework shrinkage. At the same time, a sharp adsorption at $P / P_{0}=1.0$ is observed, which gives a hint of the exposure of macropores formed by carbonization. HPCM-1-900 shows a BET surface area of $517 \mathrm{~m}^{2} / \mathrm{g}$ and pore volume of 0.33 $\mathrm{cm}^{3} / \mathrm{g}$ (Table 1). However, the mesoporosity of the polymer monolith HPCM-1-350 cannot be replicated, which may be ascribed to the small pore windows and unground monolithic sample.

\subsection{Hexagonal mesostructure of HPCM-2}

By decreasing the ratio of resol to triblock copolymer F127, a 2-D hexagonal mesostructured HPCM-2 was obtained. The SAXS pattern of the hierarchically porous carbonaceous monolith HPCM-2-130 shows one strong scattering peak and two resolved weak peaks (Fig. 1(b) a), which can be indexed as 10, 11, and 31 reflections of a 2-D hexagonal mesostructure with the space group p6mm. After calcination at $350{ }^{\circ} \mathrm{C}$ in $\mathrm{N}_{2}$ flow for $3 \mathrm{~h}$, the 11 and 31 scattering peaks in the SAXS pattern of polymer monolith HPCM-2-350 (Fig. 1(b) b) become better resolved and shift to higher $q$ values than those for HPCM-2-130. Together with the presence of 10 and 20 scattering peaks, these results indicate a well ordered hexagonal p6mm mesostructure. Despite the removal of a large part of the template on calcination, the ordered mesostructure is perfectly retained. The lattice size of HPCM-2-130 ( $\left.a_{0}=16.3 \mathrm{~nm}\right)$ decreases by $11.6 \%$ to 14.4 $\mathrm{nm}$ after calcination at $350{ }^{\circ} \mathrm{C}$. After carbonization at $600{ }^{\circ} \mathrm{C}$ in $\mathrm{N}_{2}$, the SAXS patterns of HPCM-2-600 shows well-resolved 10, 11, and 31 diffraction peaks (Fig. 1(b) c), clearly indicating a thermally stable ordered hexagonal mesostructure. Because the crosslinked polymer framework transformed into a carbon framework on further calcination, the unit cell parameter of HPCM-2-600 decreases to $12.2 \mathrm{~nm}$, corresponding to a framework shrinkage of $25.1 \%$. After further carbonization at the higher temperature of $900{ }^{\circ} \mathrm{C}$, the SAXS pattern of the resulting carbonaceous monolith HPCM-2-900 becomes less resolved (Fig. 1(b) d); only 10 and weak 30 scattering peaks are observed, suggesting a degradation of the mesostructure of HPCM-2. The unit cell parameter of HPCM-2-900 decreases to $12.1 \mathrm{~nm}$, corresponding to a further shrinkage of the framework by about $1 \%$. The changes in the scattering peaks in the SAXS patterns on increasing the temperature from 600 to $900{ }^{\circ} \mathrm{C}$ reflect the significant changes in pore wall thickness and pore size on calcination (Table 1), despite the negligible change in unit cell parameter.

TEM images of the carbonaceous monolith HPCM-2-600 carbonized at $600{ }^{\circ} \mathrm{C}$ in $\mathrm{N}_{2}$ show large domains of ordered patterns (Figs. 4(a) and 4(b)), further confirming an ordered 2-D hexagonal mesostructure. The lattice parameter estimated from the TEM images is about $12.2 \mathrm{~nm}$, in good agreement with the value obtained from SAXS patterns. TEM images of mesoporous carbon HPCM-2-900 (Figs. 4(c) and $4(\mathrm{~d})$ ) also reveal large domains of typical ordered hexagonal mesostructure patterns, confirming that the $p 6 \mathrm{~mm}$ mesostructure of HPCM-2 is thermally stable. The FFT diffractograms (insets) also confirm that the typical ordered $p 6 \mathrm{~mm}$ structure is retained at high temperature. ED images and high-angle XRD patterns (the data are not shown here) confirm that

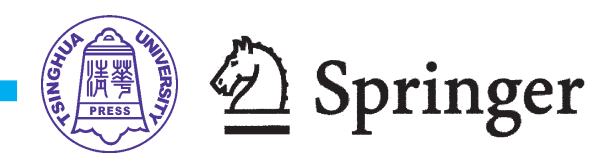




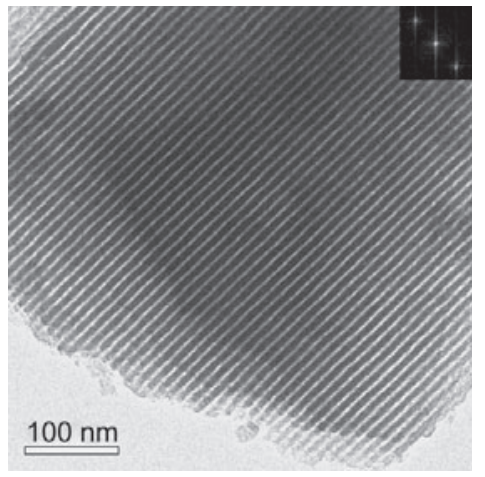

(a)

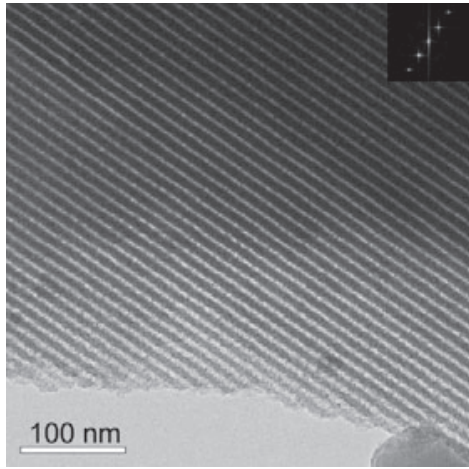

(c)

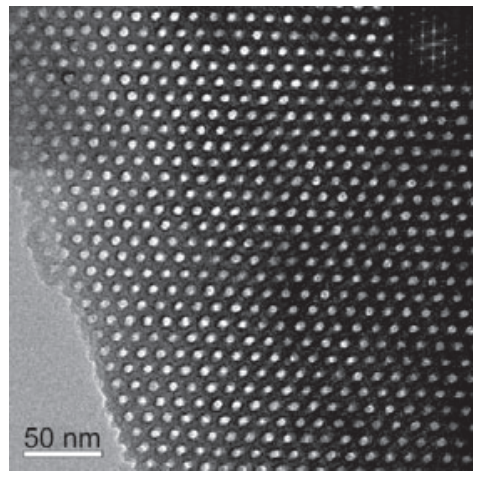

(b)

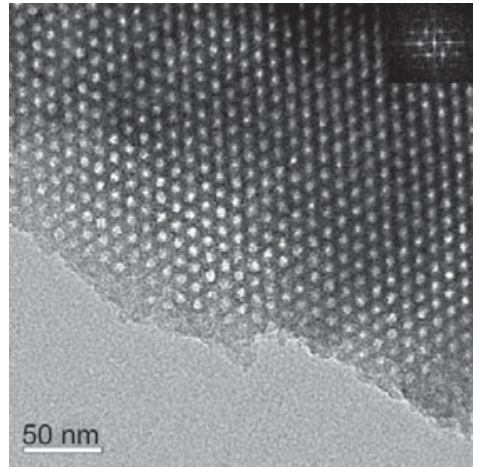

(d)

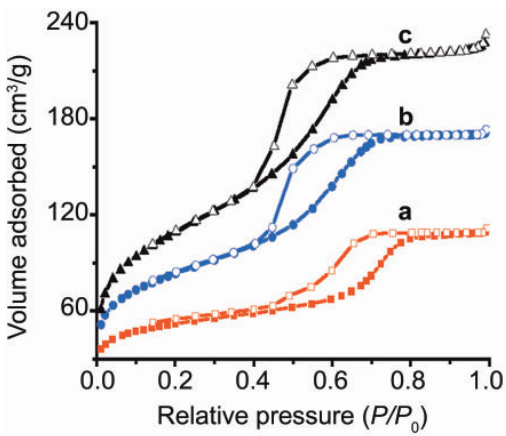

(a)

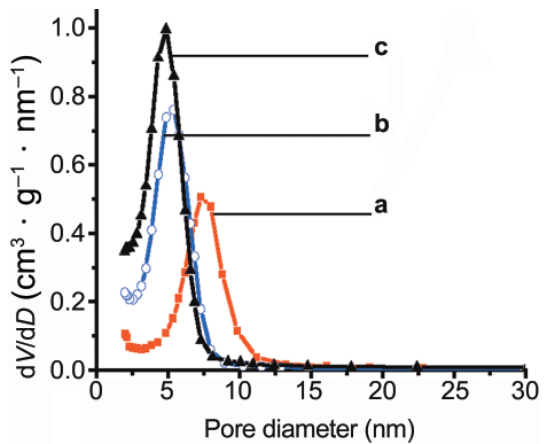

(b)

Figure $5 \quad \mathrm{~N}_{2}$ sorption isotherms (a) and pore size distributions (b) of hierarchically porous monolith HPCM-2 calcined at (a), $350{ }^{\circ} \mathrm{C}$, (b) $600{ }^{\circ} \mathrm{C}$, and (c) $900{ }^{\circ} \mathrm{C}$ [001] (b), (d) directions. The insets are the corresponding FFT diffractograms. The samples HPCM-2-600 and HPCM-2-900 were obtained by carbonizing HPCM-2-130 at 600 and $900{ }^{\circ} \mathrm{C}$ in nitrogen for $3 \mathrm{~h}$, respectively

framework of HPCM-2-900 is amorphous even after calcination at $900{ }^{\circ} \mathrm{C}$ for $3 \mathrm{~h}$.

$\mathrm{N}_{2}$ sorption isotherms of HPCM-2-350 calcined at $350{ }^{\circ} \mathrm{C}$ in $\mathrm{N}_{2}$ exhibit representative type IV curves with obvious capillary condensation steps at $P / P_{0}=0.6$ -0.8 (Fig. 5(a) a), suggesting the presence of uniform mesopores. The $\mathrm{H}_{1}$ hysteresis loop suggests that cylindrical channels are present [21]. A narrow pore size distribution with a mean value of $7.5 \mathrm{~nm}$ can also be calculated from the adsorption branch based on the BJH model (Fig. 5(b) a). The BET surface area is $200 \mathrm{~m}^{2} / \mathrm{g}$ and the pore volume is $0.17 \mathrm{~cm}^{3} / \mathrm{g}$ (Table 1). After carbonization at $600{ }^{\circ} \mathrm{C}$ in $\mathrm{N}_{2}$, capillary condensation steps at $P / P_{0}=0.4-0.75$ and a $\mathrm{H}_{1}$ type hysteresis loop are also observed for HPCM-2-600 (Fig. 5(a) b), suggesting that cylindrical mesochannels are retained [21]. HPCM-2-600 shows a narrow pore size distribution with a mean value of 5.4 $\mathrm{nm}$, corresponding to pore size shrinkage of about $28 \%$. The BET surface area and total pore volume are calculated to be $540 \mathrm{~m}^{2} / \mathrm{g}$ and $0.38 \mathrm{~cm}^{3} / \mathrm{g}$, respectively (Fig. 5(b) b). After further calcination at $900{ }^{\circ} \mathrm{C}$, the capillary condensation step of the ordered carbonaceous monolith HPCM-2-900 becomes steep and shifts to low relative pressure $P / P_{0}=0.4$ -0.65 (Fig. $5(\mathrm{a}) \mathrm{c}$ ), which is related to the reduction of aperture size to $4.9 \mathrm{~nm}$ (Fig. 5(b) c). The $\mathrm{H}_{2}$ hysteresis loop of HPCM-2-900 suggests that it has imperfect cylindrical channels, implying the presence of cucurbit-like rough surfaces caused by asymmetric pore shrinkage. HPCM-2-900 shows increased values of BET surface area of $870 \mathrm{~m}^{2} / \mathrm{g}$ and total pore volume of $0.58 \mathrm{~cm}^{3} / \mathrm{g}$, since the template is further removed after calcination at $900{ }^{\circ} \mathrm{C}$.

\subsection{Morphology and macroporous structure of HPCM}

The as-prepared samples HPCM-130 have the same volume as the PU foam scaffold. Taking HPCM-2 as an example, after calcination at $350{ }^{\circ} \mathrm{C}$ in $\mathrm{N}_{2}$, the resulting HPCM-2-350 turns a brown color. It retains 

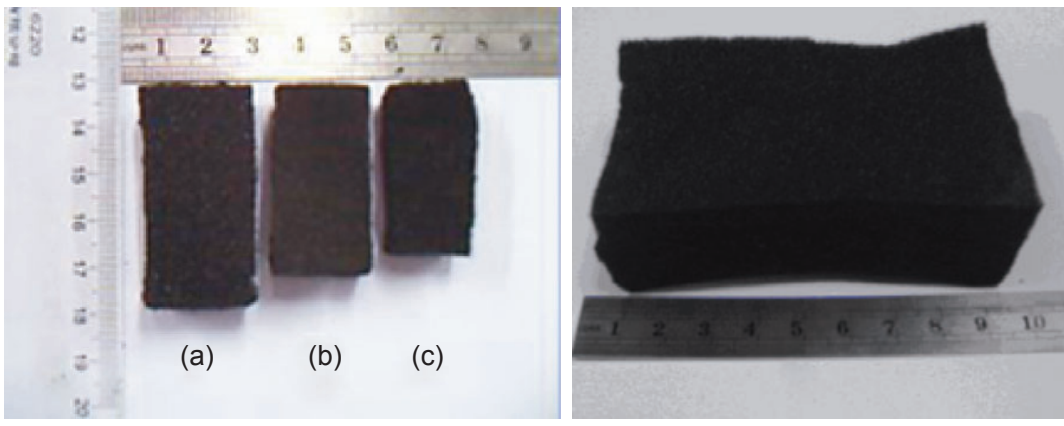

(d)

Figure 6 Photographs of hierarchically porous carbonaceous monolith HPCM-2 calcined at (a) 350 , (b) 600 , (c) and (d) $900^{\circ} \mathrm{C}$

the foam-like architecture with some macrostructural shrinkage, suggesting a good thermal stability of the macroporous architecture (Fig. 6(a)). After calcination at $600{ }^{\circ} \mathrm{C}$ in $\mathrm{N}_{2}$, the resulting HPCM-2-600 has a black color. Although the HPCM-2 polymer framework evolves into a homologous carbon texture, the monolithic morphology of HPCM-2-600 is still well preserved (Fig. 6(b)). After further carbonization at $900{ }^{\circ} \mathrm{C}$ in $\mathrm{N}_{2}$, HPCM-2-900 shows about $68 \%$ shrinkage in volume but still preserves the macrostructure morphology despite the polymer being further converted into carbonaceous species (the linear shrinkage is about $32 \%$ ); this is also indicative of a good thermal stability (Fig. 6(c)). Bulk carbonaceous monoliths of HPCM-2-900 with large volume were also prepared (Fig. 6(d)). All the samples replicate the macrostructure of the PU foam scaffold, suggesting the effective templating role of the scaffold.

The 3-D interconnecting network of the PU foam scaffold is revealed by the SEM image shown in Fig. 7(a). The macropore sizes are in the range 200-500 $\mu \mathrm{m}$. Its 3-D interconnecting struts are ideal interfaces for the selfassembly. SEM images of HPCM-2-130 (Fig. 7(b)) reveal that the width of the struts increases to about $88 \mu \mathrm{m}$ and their surface turns smooth since the carbon precursors are coated onto them. The thickness of the coating estimated from SEM results is approximately $11 \mu \mathrm{m}$. After carbonization at $600{ }^{\circ} \mathrm{C}$ in $\mathrm{N}_{2}$, the SEM images of HPCM-2-600 also show its 3-D macrostructure exactly replicates the skeleton of the PU foam sacrificial scaffold (Fig. 7(c)). The interconnecting macropores are well retained except for some shrinkage. The size of the solid struts is reduced to about $50 \mu \mathrm{m}$, due to the uniform framework shrinkage during the calcination process. The macropore sizes evolved into the range $150-450 \mu \mathrm{m}$. The SEM image of the cross section of HPCM-2-600 shows that the struts of the mesoporous carbonaceous material

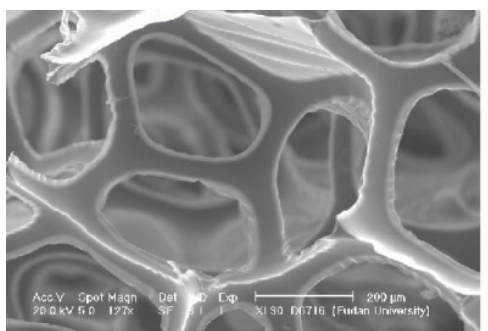

(a)

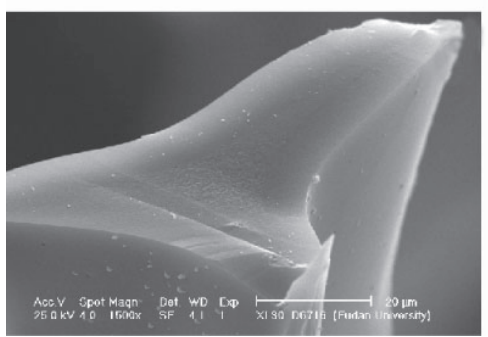

(d)

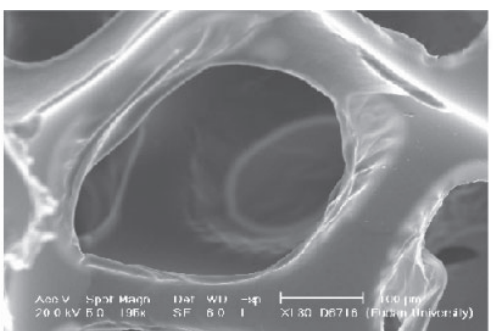

(b)

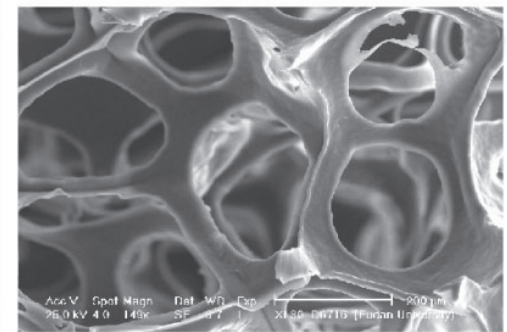

(e)

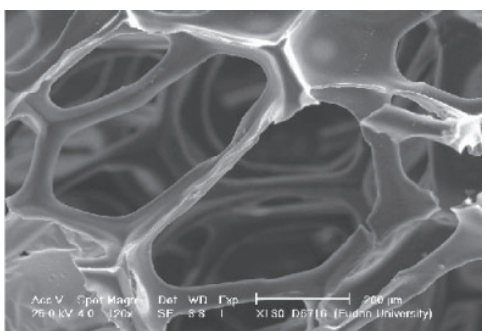

(c)

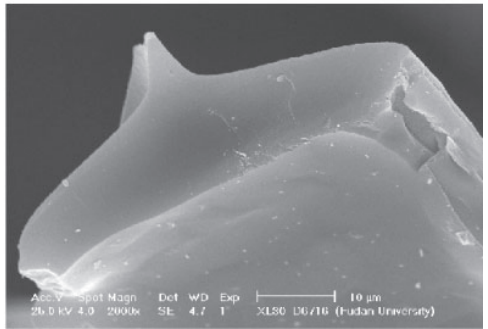

(f)

Figure 7 SEM images of (a) PU foam scaffold; (b) hierarchically porous carbonaceous monolith HPCM-2-130 prepared by the EISA method on the PU foam scaffold; (c) hierarchically porous monolith HPCM-2-600 obtained by calcination at $600{ }^{\circ} \mathrm{C}$; (d) the cross section of struts of HPCM-2-600; (e) hierarchically porous monolith HPCM-2-900 obtained by calcination at $900{ }^{\circ} \mathrm{C}$; (f) the cross section of struts of HPCM-2-900 
are solid (Fig. 7(d)), consistent with them being the remains of PU foam struts. The uniform thickness of the mesostructured composite suggests the coating process occurs homogeneously at the interfaces in different directions. After further calcination at $900{ }^{\circ} \mathrm{C}$ in nitrogen, HPCM-2-900 with macropores of 100-300 $\mu \mathrm{m}$ still shows 3-D macrostructure architecture (Fig. 7(e)). The cross section of the strut still shows the solid cable-like structure (Fig. 7(f)), implying that a small amount of residual PU foam remains. Finally, mesoporous carbonaceous products with solid pencillike structures are obtained. The core is composed of a small amount of amorphous carbon residue derived from the decomposition of the PU foam.

The TGA curve of the copolymer template F127 in $\mathrm{N}_{2}$ flow shows a weight loss of about 93 wt $\%$ below $380{ }^{\circ} \mathrm{C}$ and a further small weight loss above $400{ }^{\circ} \mathrm{C}$ (Fig. 8(a)), suggesting that the triblock copolymer template can be removed by calcination at $350{ }^{\circ} \mathrm{C}$ in $\mathrm{N}_{2}$. Pure PU foam scaffolds display two notable weight losses at about 280 and $367^{\circ} \mathrm{C}$, which correspond to the observed weight loss of 94 wt $\%$ below $400{ }^{\circ} \mathrm{C}$ (Fig. 8(b)). No noticeable weight loss can be detected above $400{ }^{\circ} \mathrm{C}$, suggesting that most of the PU foam scaffold can be decomposed by calcination at $350{ }^{\circ} \mathrm{C}$ in $\mathrm{N}_{2}$, in agreement with previous reports [26, 29]. The TGA curve of HPCM-2-130 shows a weight loss (11 wt\%) at about $270{ }^{\circ} \mathrm{C}$, corresponding to partial decomposition of the PU foam scaffold (Fig. 8(c)). The DTG curve (Fig. 8 , inset) also confirms that the temperature range of decomposition of HPCM-2-130 is coincident with

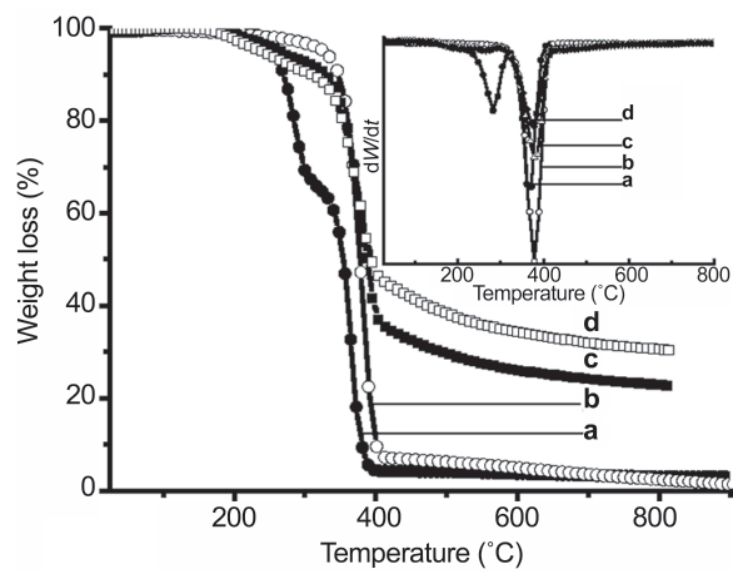

Figure 8 TGA and DTG (inset) curves in nitrogen of (a) PU foam, (b) Pluronic F127, (c) HPCM-2-130, and (d) HPCM-1-130 that of the PU foam scaffold. A significant weight loss (60 wt\%) is observed at about $385^{\circ} \mathrm{C}$, which is mainly accounted for by the decomposition of triblock copolymer F127 template and PU foam scaffold. A weight loss of $7 \mathrm{wt} \%$ in the range $400-900{ }^{\circ} \mathrm{C}$ is detected, which may be related to the polymerization of phenolic resins and further decomposition of PU foam [29]. It is reasonable that the PU foam scaffold only decomposes slowly at temperatures above $400{ }^{\circ} \mathrm{C}$, because it is tightly packed with the mesoporous resin coating. The total weight loss of HPCM-2-130 is about $81 \mathrm{wt} \%$ (Fig. 8(c)). The TGA curve for the hierarchically carbonaceous monolith HPCM-1-130 shows a weight loss of $66.6 \mathrm{wt} \%$ below $400{ }^{\circ} \mathrm{C}$ (Fig. 8(d)). That means that the content of resol in HPCM-1-130 is a little higher than that in HPCM-2-130.

Elemental analysis shows that the mass ratio of $\mathrm{N}: \mathrm{C}: \mathrm{H}$ is 2.6:75.1:5.3 for HPCM-1-350 (Table 1). After carbonization at $600{ }^{\circ} \mathrm{C}$, the mass ratio of $\mathrm{N}: \mathrm{C}: \mathrm{H}$ becomes 2.1:77.3:8.7 for HPCM-1-600 because of the further decomposition of the PU foam scaffold. After further carbonization at $900{ }^{\circ} \mathrm{C}$, the $\mathrm{N}: \mathrm{C}: \mathrm{H}$ mass ratio for HPCM-1-900 changes to 1.2:84.4:2.1, suggesting an increase of carbon content and further decomposition of PU foam scaffold. Elemental analysis indicates that the mass ratio of $\mathrm{N}: \mathrm{C}: \mathrm{H}$ is $4.3: 77.1: 5.1$ for HPCM-2-350 calcined at $350{ }^{\circ} \mathrm{C}$ in $\mathrm{N}_{2}$ (Table 1). After further carbonization at $900{ }^{\circ} \mathrm{C}$, the mass ratio of $\mathrm{N}$ : $\mathrm{C}: \mathrm{H}$ for HPCM-2-900 is 1.9:75.4:2.1, also suggesting further decomposition of the PU foam scaffold. The TGA and elemental analysis results suggest that the hierarchically porous monolith HPCM-2-900 is mainly composed of carbon.

The FT-IR spectrum of the hierarchically carbonaceous monolith HPCM-1-130 shows a strong and broad band at around $3400 \mathrm{~cm}^{-1}$ arising from $\mathrm{N}$ $-\mathrm{H}$ and $\mathrm{O}-\mathrm{H}$ vibrations (Fig. 9(a) a), consistent with the presence of $\mathrm{N}-\mathrm{H}$ groups of $\mathrm{PU}$ foam, phenolic $\mathrm{O}$ $-\mathrm{H}$ groups and uncrosslinked benzyl alcohol [30, 31]. The band at around $1630 \mathrm{~cm}^{-1}$ is attributed to $\mathrm{C}-\mathrm{C}$, $\mathrm{N}-\mathrm{H}$, and $\mathrm{C}-\mathrm{N}$ stretching and substituted aromatic ring structures, implying that the framework of HPCM-1-130 is composed of phenolic resins and PU foam [30, 31]. The band at $1480-1440 \mathrm{~cm}^{-1} \mathrm{can}$ be attributed to $\mathrm{C}-\mathrm{H}$ bending [30]. The absorption band at $1100 \mathrm{~cm}^{-1}$ can be assigned to $\mathrm{C}-\mathrm{N}$ and $\mathrm{C}-$ 


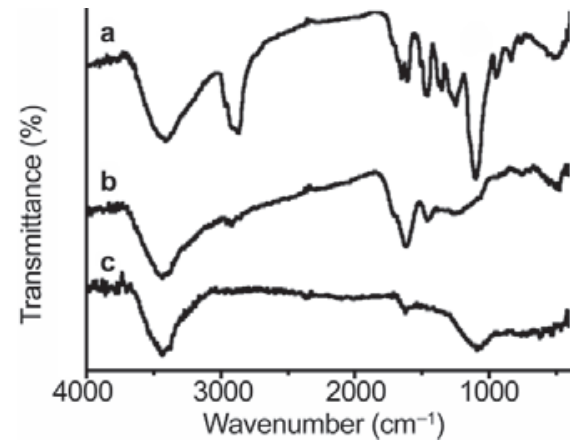

(a)

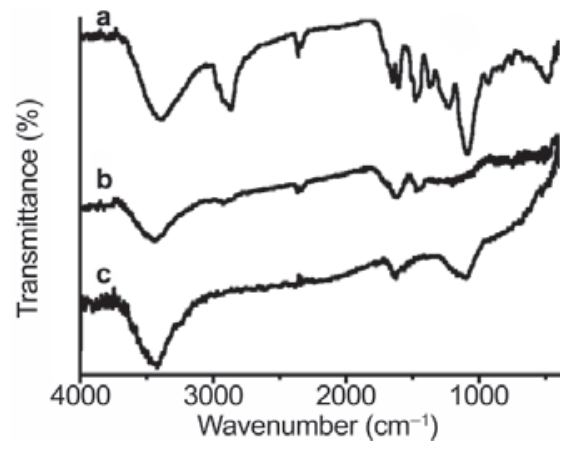

(b)

Figure 9 FT-IR spectra of HPCM-1 (a) and HPCM-2 (b): a, as-made; b, calcined at $350{ }^{\circ} \mathrm{C}$; $\mathbf{c}$, calcined at $900{ }^{\circ} \mathrm{C}$ in nitrogen

O stretching modes and that around $2900 \mathrm{~cm}^{-1}$ to C $-\mathrm{H}$ stretching modes of F127 and PU foam [30, 32]. The absorption band at $1370 \mathrm{~cm}^{-1}$ can be assigned to the $\mathrm{C}-\mathrm{N}$ stretching bands of PU foam [32]. After calcination at $350{ }^{\circ} \mathrm{C}$ under $\mathrm{N}_{2}$ (Fig. 9(a) b), the bands at 1100 and $2900 \mathrm{~cm}^{-1}$ almost disappeared, implying the decomposition and removal of the template. After calcination at $900{ }^{\circ} \mathrm{C}$ in $\mathrm{N}_{2}$, the band at 1100 $\mathrm{cm}^{-1}$ assigned to the ether $\mathrm{C}-\mathrm{O}$ bond remains, which can be ascribed to the presence of phenol groups. The FT-IR spectrum (Fig. 9(a) c) of mesoporous carbon monolith HPCM-1-900 after carbonization at $900{ }^{\circ} \mathrm{C}$ shows that the characteristic band of the templates at $2900 \mathrm{~cm}^{-1}$ and the characteristic vibration bands for phenolic resins disappeared. The evolution of the FT-IR vibration bands indicates the variation in framework constitution with temperature, and is in good agreement with the elemental analysis results (Table 1). The FT-IR spectra (Fig. 9(b)) of the hierarchically carbonaceous monolith HPCM-2 show similar results to those for HPCM-1.

\subsection{Fabrication process of the HPCM materials}

According to above results, the EISA procedure on the PU foam scaffold facilitates the required interfacial assembly and is a facile approach for the preparation of multimodal porous monolith materials on a large-scale. Firstly, a sol solution was prepared with the designated carbon precursor (resol) and the triblock copolymer template. The commercial PU foam with its ramified struts provides the space for solvent evaporation and interface for organicorganic self-assembly. Most of the macropore spaces of PU foam remain and serve as the pathway for the solvent volatilization. Secondly, after the ethanol had completely evaporated, the thermopolymerization treatment is carried out and the hierarchically carbonaceous monolith is obtained. Thirdly, calcination is carried out in inert atmosphere at different temperatures to obtain hierarchically porous carbonaceous monoliths. During the calcination, the amphiphilic triblock copolymer template and most of PU foam scaffold can be removed at around $350{ }^{\circ} \mathrm{C}$, and ordered mesoporous polymers with different structure are obtained on the surface of the PU foam struts. Because of the uniform shrinkage of the mesostructured carbonaceous layers and fast decomposition of the PU foam sacrificial scaffold, hierarchically porous carbon monoliths with the desired macrostructure can be obtained after further carbonization at high temperatures (600 $-900{ }^{\circ} \mathrm{C}$ ). It is found that the original macroporous architecture with its 3-D interconnecting struts is retained during all the steps. The TGA results, similar to previous reports, show that more than $94 \%$ of the PU foam can be removed during the carbonization treatment $[26,29]$. With the increase of the amount of F127 template in the sol solution, the mesostructure phase transforms from body-centered cubic $\operatorname{Im} \overline{3} m$ to a 2-D hexagonal $p 6 \mathrm{~mm}$ structure. Carbonaceous monoliths with different mesostructures can be successfully prepared. The pathway described here should be capable of extension to the synthesis of other mesostructures materials such as cubic bicontinuous $I a \overline{3} d$ and lamellar mesophases.

Compared with the solution coating method carried out on planar substrates, our approach presented here for the preparation of hierarchically porous monoliths from commercially available and cheap chemicals is suitable for mass production. In addition, the monolith morphology can also minimize the volume required for carbonization, lowering the costs of production. The simplified sol preparation process and direct carbonization to the final product also offer advantages in terms 
of mass production. This method can be extended to the synthesis of porous monoliths with different compositions, such as silica, apatites, alumina and so on. The resulting hierarchically porous carbonaceous materials should be very useful in electrochemical double layered capacitors, separation, as adsorbents for wastewater treatment, and in sensors.

\section{Conclusions}

A facile approach for fabrication of hierarchically porous carbonaceous monoliths with ordered mesostuctures is demonstrated by using organicorganic assembly on a thermally decomposable monolithic PU foam scaffold. Hierarchically porous carbonaceous monoliths HPCM-1 and HPCM-2 have readily been prepared by using the EISA method with resol as a carbon precursor and triblock copolymer F127 as a mesostructural template on the 3-D interconnecting struts of a PU foam scaffold. The resulting products replicate the skeleton of the PU foam scaffold with macropore sizes in the range 100 $-450 \mu \mathrm{m}$. The macrostructural skeleton is composed of a large number of grapevine struts with a diameter of about $50 \mu \mathrm{m}$. The struts are pencil-like solids because of the homogenous shrinking of ordered mesostructured carbonaceous shells and amorphous carbon cores. The mesostructure can be varied from ordered 3-D body-centered cubic $(\operatorname{Im} \overline{3} m)$ to 2-D hexagonal $(p 6 \mathrm{~mm})$ by simply changing the ratio of resol precursor to copolymer template. The hierarchically porous carbonaceous monoliths exhibit tunable uniform mesopores (3.8-7.5 nm), high BET surface areas $\left(200-870 \mathrm{~m}^{2} / \mathrm{g}\right)$, and large pore volumes $\left(0.17-0.58 \mathrm{~cm}^{3} / \mathrm{g}\right)$. This approach is very amenable to scaling up, allowing the mass production of ordered mesoporous polymer/carbon materials.

\section{Acknowledgements}

This work was supported by the National Natural Science Foundation of China (20721063, 20890123, and 20521140450), the State Key Basic Research Program of China (2006CB932302 and 2006CB202502), Shanghai Leading Academic Discipline Project (B108) and the Graduate Student Innovation Foundation of
Fudan University (EYH1615047).

Electronic Supplementary Material: The SAXS pattern of the PU foam scaffold is available in the online version of this article at http://dx.doi. org / 10.1007/s12274-009-9022-y and is accessible free of charge.

\section{References}

[1] Wan, Y.; Shi, Y. F.; Zhao, D. Y. Supramolecular aggregates as templates: Ordered mesoporous polymers and carbons. Chem. Mater. 2008, 20, 932-945.

[2] Fan, L. Z.; Hu, Y. S.; Maier, J.; Adelhelm, P.; Smarsly, B.; Antonietti, M. High electroactivity of polyaniline in supercapacitors by using a hierarchically porous carbon monolith as a support. Adv. Funct. Mater. 2007, 17, 3083-3087.

[3] Zhao, Y.; Zheng, M. B.; Cao, J. M.; Ke, X. F.; Liu, J. S.; Chen, Y. P.; Tao, J. Easy synthesis of ordered meso/macroporous carbon monolith for use as electrode in electrochemical capacitors. Mater. Lett. 2008, 62, 548-551.

[4] Li, F.; Wang, Z.; Ergang, N. S.; Fyfe, C. A.; Stein, A. Controlling the shape and alignment of mesopores by confinement in colloidal crystals: Designer pathways to silica monoliths with hierarchical porosity. Langmuir 2007, 23, 3996-4004.

[5] Imhof, A.; Pine, D. J. Uniform macroporous ceramics and plastics by emulsion templating. Adv. Mater. 1998, 10, 697-700.

[6] Caruso, F.; Caruso, R. A.; Möhwald, H. Production of hollow microspheres from nanostructured composite particles. Chem. Mater. 1999, 11, 3309-3314.

[7] Yan, H.; Blanford, C. F.; Holland, B. T.; Smyrl, W. H.; Stein, A. General synthesis of periodic macroporous solids by templated salt precipitation and chemical conversion. Chem. Mater. 2000, 12, 1134-1141.

[8] Wakayama, H.; Fukushima, Y. Nanoporous silica prepared with activated carbon molds using supercritical $\mathrm{CO}_{2}$. Chem. Mater. 2000, 12, 756-761.

[9] Deng, Y. H.; Liu, C.; Liu, J.; Zhang, F.; Yu, T.; Zhang, F. Q.; Gu, D., Zhao, D. Y. A novel approach to the construction of 3-D ordered macrostructures with polyhedral particles. J. Mater. Chem. 2008, 18, 408-415.

[10] Taguchi, A.; Smatt, J. H.; Linden, M. Carbon monoliths possessing a hierarchical, fully interconnected porosity. 
Adv. Mater. 2003, 15, 1209-1211.

[11] Shi, Z. G.; Feng, Y. Q.; Xu, L.; Da, S. L. Zhang, M. Synthesis of a carbon monolith with trimodal pores. Carbon 2003, 41, 2677-2679.

[12] Alvarez, S.; Esquena, J.; Solans, C.; Fuertes, A. B. Meso/ macroporous carbon monoliths from polymeric foams. Adv. Eng. Mater. 2004, 6, 897-899.

[13] Lu, A. H.; Li, W. C.; Schmidt, W.; Schuth, F. Fabrication of hierarchically structured carbon monoliths via selfbinding and salt templating. Micropor. Mesopor. Mater. 2006, 95, 187-192.

[14] Lu, A. H.; Smatt, J. H.; Backlund, S.; Linden, M. Easy and flexible preparation of nanocasted carbon monoliths exhibiting a multimodal hierarchical porosity. Micropor. Mesopor. Mater. 2004, 72, 59-65.

[15]Wang, L. F.; Lin, S.; Lin, K. F.; Yin, C. Y.; Liang, D. S. Di, Y.; Fan, P. W. Jiang, D. Z.; Xiao, F. S. A facile synthesis of highly ordered mesoporous carbon monolith with mechanically stable mesostructure and superior conductivity from SBA-15 powder. Micropor. Mesopor. Mater. 2005, 85, 136-142.

[16] Deng, Y. H.; Liu, C.; Yu, T.; Liu, F.; Zhang, F. Q.; Wan, Y.; Zhang, L. J.; Wang, C. C.; Tu, B.; Webley, P. A.; Wang, H. T.; Zhao, D. Y. Facile synthesis of hierarchically porous carbons from dual colloidal crystal/block copolymer template approach. Chem. Mater. 2007, 19, 3271-3277.

[17] Feng, P. Y.; Bu, X. H.; Stucky, G. D. Pine, D. J. Monolithic mesoporous silica templated by microemulsion liquid crystals. J. Am. Chem. Soc. 2000, 122, 994-995.

[18] Yang, H. F.; Shi, Q. H.; Tian, B. Z.; Xie, S. H.; Zhang, F. Q. Yan, Y.; Tu, B.; Zhao, D. Y. A fast way for preparing crack-free mesostructured silica monolith. Chem. Mater. 2003, 15, 536-541.

[19] Liang, C. D.; Hong, K. L.; Guiochon, G. A.; Mays, J. W.; Dai, S. Synthesis of a large-scale highly ordered porous carbon film by self-assembly of block copolymers. Angew. Chem. Int. Ed. 2004, 43, 5785-5789.

[20] Liang, C. D.; Dai, S. Synthesis of mesoporous carbon materials via enhanced hydrogen-bonding interaction. J. Am. Chem. Soc. 2006, 128, 5316-5317.

[21] Meng, Y.; Gu, D.; Zhang, F. Q.; Shi, Y. F.; Yang, H. F.; Li, Z.; Yu, C. Z.; Tu, B.; Zhao, D. Y. Ordered mesoporous polymers and homologous carbon frameworks: Amphiphilic surfactant templating and direct transformation. Angew. Chem. Int. Ed. 2005, 44, 7053-7059.

[22] Meng, Y.; Gu, D.; Zhang, F. Q.; Shi, Y. F.; Cheng, L.;
Feng, D.; Wu, Z. X.; Chen, Z. X.; Wan, Y.; Stein, A.; Zhao, D. Y. A family of highly ordered mesoporous polymer resin and carbon structures from organic-organic selfassembly. Chem. Mater. 2006, 18, 4447-4464.

[23] Huang, Y.; Cai, H. Q.; Yu, T.; Zhang, F. Q.; Zhang, F.; Meng, Y.; Gu, D.; Wan, Y.; Sun, X. L.; Tu, B.; Zhao, D. Y. Formation of mesoporous carbon with a face-centeredcubic $F d \overline{3} m$ structure and bimodal architectural pores from the reverse amphiphilic triblock copolymer PPOPEO-PPO. Angew. Chem. Int. Ed. 2007, 46, 1089-1093.

[24] Deng, Y. H.; Yu, T.; Wan, Y.; Shi, Y. F.; Meng, Y.; Gu, D.; Zhang, L. J.; Huang, Y.; Liu, C.; Wu, X. J.; Zhao, D. $Y$. Ordered mesoporous silicas and carbons with large accessible pores templated from amphiphilic diblock copolymer poly(ethylene oxide)-b-polystyrene. J. Am. Chem. Soc. 2007, 129, 1690-1697.

[25] Tanka, S.; Nishiyama, N.; Egashira, Y.; Ueyama, K. Synthesis of ordered mesoporous carbons with channel structure from an organic-organic nanocomposite. Chem. Commun. 2005, 16, 2125-2127.

[26] Xue, C. F.; Tu, B.; Zhao, D. Y. Evaporation-induced coating and self-assembly of ordered mesoporous carbon-silica composite monoliths with macroporous architecture on polyurethane foams. Adv. Funct. Mater. 2008, 18, 3914-3921.

[27] Ravikovitch, P. I.; Neimark, A. V. Density functional theory of adsorption in spherical cavities and pore size characterization of templated nanoporous silicas with cubic and three-dimensional hexagonal structures. Langmuir 2002, 18, 1550-1560.

[28] Schmidt, W. Calculation of XRD patterns of simulated FDU-15, CMK-5, and CMK-3 carbon structures. Micropor. Mesopor. Mater. 2009, 117, 372-379.

[29] Inagaki, M.; Morishita, T.; Kuno, A.; Kito, T.; Hirano, M.; Suwa, T.; Kusakawa, K. Carbon foams prepared from polyimide using urethane foam template. Carbon 2004, 42, 497-502.

[30] Trick, K. A.; Saliba, T. E. Mechanisms of the pyrolysis of phenolic resin in a carbon/phenolic composite. Carbon 1995, 33, 1509-1515.

[31]Konig, A.; Kroke, E. Synthesis of carbon-rich hybrid foam from GAP-modified polyurethane. Propellants Explos. Pyrotech. 2008, 33, 373-380.

[32] Hatchett, D. W.; Kodippili, G.; Kinyanjui, J. M.; Benincasa, F.; Sapochak, L. FTIR analysis of thermally processed PU foam. Polym. Degrad. Stab. 2005, 87, 555-561. 